\title{
Ortopedik Uygulamalarda Bilgisayarlı Denetim Sistemi
}

\author{
Ercan AVŞAR ${ }^{1}$, İbrahim D. AKÇALI ${ }^{* 2}$, Ahmet AYDIN ${ }^{1}$, M. Kerem ÜN ${ }^{1}$,

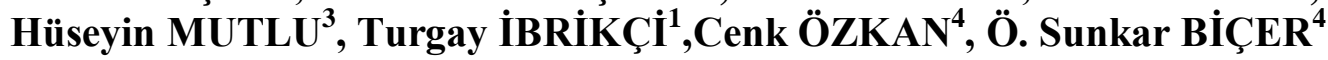 \\ ${ }^{I}$ Çukurova Üniversitesi, Elektrik-Elektronik Müh. Bölümü, Adana \\ ${ }^{2}$ Çukurova Üniversitesi, Makine Alet Cihaz Tasarım Imalat Arş.ve Uygulama Mrk, Adana \\ ${ }^{3}$ Mersin Üniversitesi, Makina Mühendisliği Bölümü, Mersin \\ ${ }^{4}$ Çukurova Üniversitesi, Tıp Fakültesi, Ortopedi ve Travmatoloji ABD., Adana
}

Geliş tarihi:07.09.2015

Kabul tarihi:25.12.2015

\section{Özet}

$\mathrm{Bu}$ çalışmada, ortopedi alanında farklı amaçlar için kullanılmakta olan harici fiksatörlerin etkili kullanımını sağlayacak olan bir bilgisayarlı denetim sistemi tanıtılmıştır. Bu bilgisayar sistemiyle, çubuk boylarını faklı fonksiyonel modellere uygun olacak şekilde değiştirerek, fiksatörün tedavi süresince tekil konuma gelme ihtimali azaltılmıştır. Ayrıca öngörülen tedaviye ait olan 3-boyutlu simülasyon ile doktora, tedaviye başlamadan önce kemiğin izleyeceği yolu görselleştirme olanağı sağlanmıştır.

Anahtar Kelimeler : Ortopedi, Harici fiksatör, Tekillik, Simülasyon

\section{A Computer Aided Control System in Orthopaedic Applications}

\begin{abstract}
In this work, a computer aided control system enabling effective usage of external fixators that are widely utilized in orthopaedics for various purposes is presented. With this system, possibility for fixator to fall into a singular position througout the treatment is reduced by cahnging its rod lengths according to various functional models. Furthermore, a 3D simulation belonging to proposed treatment scheme is provided to allow the doctor visually inspect the treatment process before it is initialized.
\end{abstract}

Keywords : Orthopaedics, External fixator, Singularity, Simulation

\footnotetext{
* Yazışmaların yapılacağı yazar: İbrahim Deniz AKÇALI, Çukurova Üniversitesi, Makine Alet Cihaz Tasarım Imalat Araștırma ve Uygulama Merkezi, Adana, idakcali@cu.edu.tr
} 


\section{GİRIŞ}

Birçok faklı alanda uygulaması bulunan GoughStewart platformu [1], ortopedide de harici fiksatör olarak kemik fragmanlarının istenilen şekilde hareket etmesini sağlamak amaciyla kullanılan bir robotik sistemdir. Geçmiş yıllarda fiksatör mekaniği alnında yapılan çalışmalar ışığında yaygınlaşmaya başlayan harici fiksatör etkinliklerinde [2-9] İlizarov'un [10] halka fiksatörü geliştirmesi yeni ve büyük bir adım olarak ortaya çıkmıştır [11]. Günümüzde yaygın olarak kullanilan Gough-Stewart platformu tipindeki modern harici fiksatörün temelleri İlizarov'un bu yöntemine dayanmaktadır. Boy uzatma, deformite düzeltme, fragman hizalama gibi amaçlarla kullanılan harici fiksatörlerin tedavi sürecine dahil edilmesi, fiksatöre ve hastaya ait çok sayıda parametrenin ortaya çıkmasına sebep olmaktadır. $\mathrm{Bu}$ parametreler X-ray görüntülerinden okunmakta [12] ve uygun biçimde matematiksel hesaplara dahil edilmektedir $[13,14]$. Fakat bu parametrelerin sayısının fazla olması ve matematik hesaplarının işlem yükü, harici fiksatörlerle birlikte bilgisayarlı bir sistemden faydalanmayı mecbur kılmaktadır. Ayrıca, fiksatörün, hasta sağlığı için risk oluşturan tekil konuma tedavi boyunca gelmeyeceğinden emin olmak gerekmektedir. $\mathrm{Bu}$ amaçla, tedaviye başlanmadan önce fiksatörün tüm tedavi süresince alacağı konumları hesaplayarak uygun şekilde tekillik analizi yapmak ve tekil bir konuma rastlanması durumunda doktorun önceden uyarılması, sistemin güvenliği açısından çok önemlidir. Daha önceden Gough-Stewart platformu için çeşitli tekillik analizi çalışmaları yapılmış olmasına rağmen [15-20] harici fiksatör uygulamalarında tekillik analizinin yapılmış olduğu çalışmalar nispeten daha azdır [21-23]. Gough-Stewart platformunun kullanıldığı ortopedik uygulamaların bir tanesinde ise farklı yapısal kurgulamalar ile tekillikten kaçınılabileceğinden bahsedilmiş olmasına rağmen tekillik analizi yapılmamıştır [24]. Bu çalışmada ise fiksatörün sağlıksız konumdan sağlıklı konuma gelirken izleyeceği yoldaki tüm ara konumlarda tekilliğe rastlama ihtimalini azaltmak amaciyla, çubuk boyları farklı fonksiyonlara uyacak modellere göre değiştirilmiştir ve bu değişikliğin hareketli fragmanın izlediği yol üzerindeki etkisi 3-boyutlu simülasyon ile görselleştirilmiştir.

\section{METOT}

Fiksatörün robotik yapısında yirmi adet büyüklük bulunmaktadır. Bu büyüklüklerden, üst - alt halka yarıçapları $\left(R, R_{1}\right)$ sembolleriyle, mafsalların yerlerini belirleyen açısal konum parametreleri $\left(\alpha_{1}-\alpha_{6} ; \varepsilon_{1}-\varepsilon_{6}\right) \quad$ sembolleriyle ve çubuk uzunlukları $\left(L_{1}-L_{6}\right)$ ile temsil edilmektedir. Bununla birlikte, X-ray görüntülerinden elde edilen büyüklükler de şu şekilde sıralanabilir (Şekil 1-3):

- $\quad\left(\beta_{A P}, \beta_{A P}^{\prime}, \beta_{L}, \beta_{L}^{\prime}\right)$ distal fragmanın AP ve $\mathrm{L}$ görüntülerindeki açısal pozisyon,

- $\quad\left(\Psi_{A P}, \Psi_{L}\right)$ distal halka düzleminin normali ile $\mathrm{AP}$ ve $\mathrm{L}$ görüntülerindeki dikey eksen arasındaki açı,

- $\left(q_{x}, q_{y}\right)$ proksimal fragmanın proksimal halka merkezine göre olan konumu,

- $\left(r_{x}, r_{y}, r_{z}\right)$ distal fragman ekseni ile distal halka merkezinin kesişim noktasının koordinatları,

- $\quad\left(e_{x}, e_{y}, e_{z}\right)$ distal ve proksimal fragman uçları arasındaki vektörün koordinatları,

- $\left(b_{A P}, b_{L}\right)$ proksimal fragmanin AP ve L görüntülerinden ölçülen uzunluklar,

- $\left(c_{A P}, c_{L}\right)$ distal fragmanin $\mathrm{AP}$ ve $\mathrm{L}$ görüntülerinden ölçülen uzunluklar,

- $\left(\delta_{0}, \delta_{A X}\right)$ halkalar arasındaki ve fragmanlar arasındaki açılar.

$\mathrm{Bu}$ büyüklüklerin daha ayrıntılı açıklaması ve tekillik hesabının nasıl yapıldığı diğer çalışmalarda bulunmaktadır [21].

İlk ve son konum çubuk uzunlukları belli olan fiksatörün ara konum kurgulamalarında aşağıda gösterilen modellere göre çubuk uzunluklarını seçmek ve tekilliği bu şekilde ortadan kaldırmak mümkündür: Aşağıdaki modellerde $i$ indisi (1-6 arasında değişmek üzere ) çubuk numarasını $j$ indisi ise (1-n arasında değişmek üzere) tedavi adımını temsil etmektedir. " 0 " alt indisi tedavinin başlangıcındaki konumu, "n" alt indisi de 


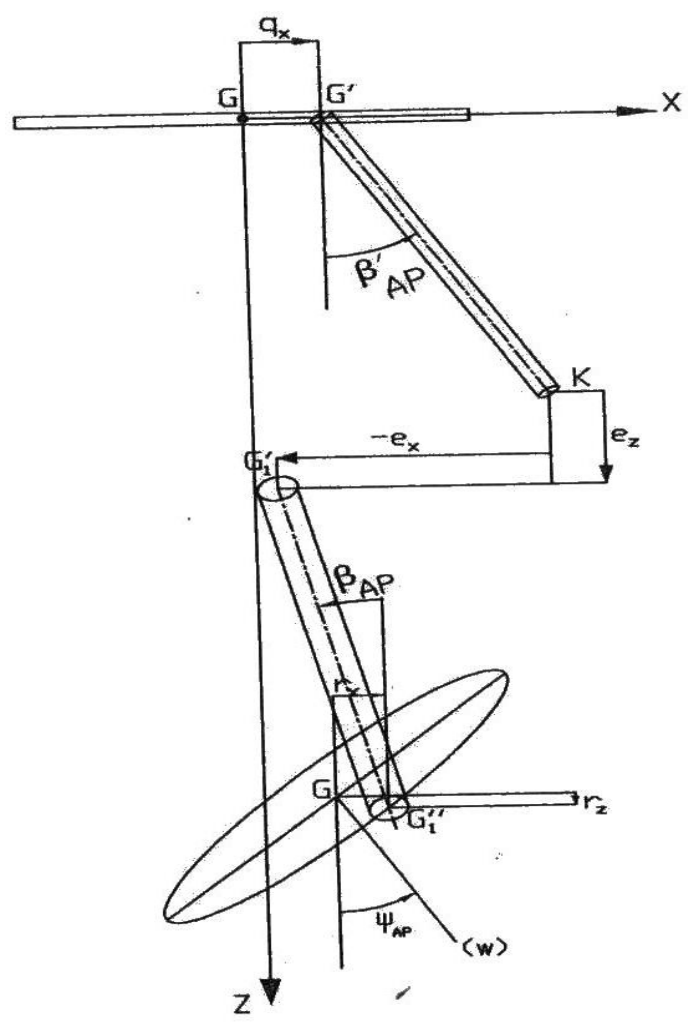

Şekil 1. Biyomekanik sistemde anterior-posterior yönde görüntü-konum ilişkisi

tedavinin son adımını simgelemektedir.

\section{i. Doğrusal Model}

$\mathrm{Bu}$ model, bütün adımların eşit alındığı ve sorgulanmadan yaygın olarak kullanılan en basit modeldir. Bu modelin matematik ifadesi aşağıda verilmiştir:

$$
L_{i j}=L_{i 0}+\left(L_{i n}-L_{i 0}\right) \frac{j}{n}
$$

\section{ii. Artan Parabolik Model}

Çubuk uzunluklarının küçük değerlerden büyük değerlere artarak belirlendiği 2. Derece model şu şekilde ifade edilebilir:

$L_{i j}=a_{0}+a_{1} j+a_{2} j^{2}$

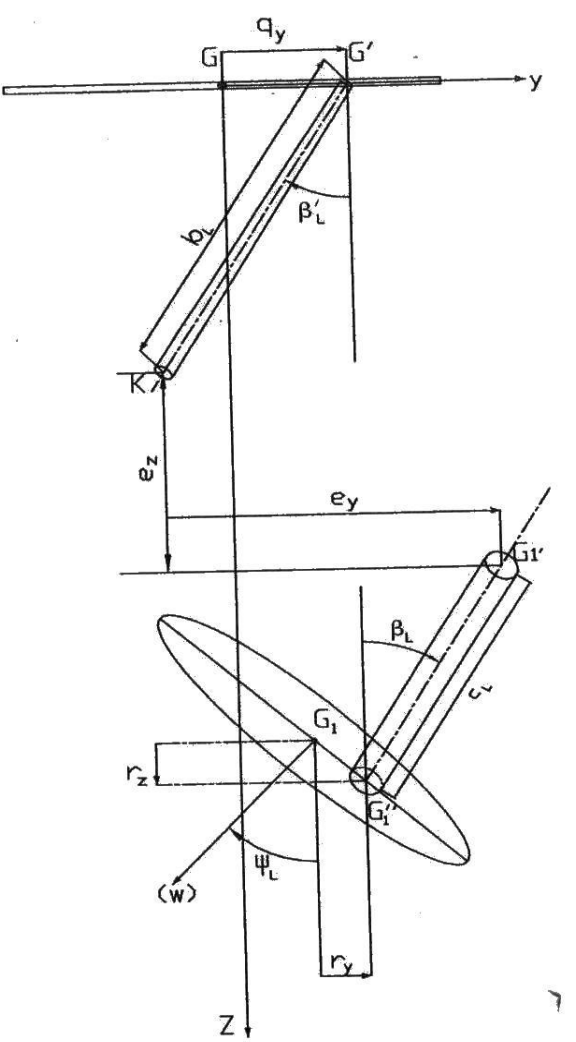

Şekil 2. Biyomekanik sistemde medial-lateral yönde görüntü-konum ilişkisi

$\mathrm{Bu}$ modelin aşağıda verilen şartları sağlaması öngörülmektedir:

$$
\begin{array}{ll}
\text { a. } & j=0 \text { ise } L_{i j}=L_{i 0} \\
\text { b. } & j=n \text { ise } L_{i j}=L_{i n} \\
\text { c. } & \left(\frac{d L_{i j}}{d j}\right)_{j=0}=0
\end{array}
$$

Yukarıdaki şartlar (2) nolu denklemde uygulanırsa şu sonuç bulunur.

$$
L_{i j}=L_{i 0}+\left(L_{i n}-L_{i 0}\right)\left(\frac{j}{n}\right)^{2}
$$

\section{iii. Azalan Parabolik Model}

Çubuk uzunluklarının küçük değerlerden büyük değerlere azalan bir hizla ulaştı̆ 12 . Derece model (2) nolu bağıntıyla ifade edilebilir. Ancak bu modelin aşağıda verilen şartları sağlaması istenir: 


$$
\begin{array}{ll}
\text { a. } & j=0 \text { ise } L_{i j}=L_{i 0} \\
\text { b. } & j=n \text { ise } L_{i j}=L_{i n} \\
\text { c. } & \left(\frac{d L_{i j}}{d j}\right)_{j=n}=0
\end{array}
$$

Yukarıdaki şartlar (2) nolu denklemde uygulanırsa şu sonuç bulunur.

$$
\begin{aligned}
L_{i j}= & L_{i 0}+2\left(L_{i n}-L_{i 0}\right) \frac{j}{n}- \\
& \left(L_{i n}-L_{i 0}\right)\left(\frac{j}{n}\right)^{2}
\end{aligned}
$$

\section{iv. Sinusoidal Model 1}

Sinusoidal model 1 aşağıdaki ifadeyle belirlenir.

$$
L_{i j}=a_{0}+a_{1} j+a_{2} \cos \frac{\pi}{n} j
$$

Bu modelin aşağıdaki şartları sağlaması beklenir.

$$
\begin{array}{ll}
\text { a. } & j=0 \text { ise } L_{i j}=L_{i 0} \\
\text { b. } & j=n \text { ise } L_{i j}=L_{i n} \\
\text { c. } & \left(\frac{d L_{i j}}{d j}\right)_{j=\frac{n}{2}}=0
\end{array}
$$

Yukarıdaki şartlar (5) nolu denklemde uygulanırsa şu sonuç bulunur.

$$
\begin{aligned}
L_{i j}= & \frac{(\pi-1) L_{i 0}-L_{i n}}{\pi-2}+ \\
& \left(\frac{L_{i n}-L_{i 0}}{n}\right)\left(\frac{\pi}{\pi-2}\right) j+ \\
& \frac{L_{i n}-L_{i 0}}{\pi-2} \cos \frac{\pi}{n} j
\end{aligned}
$$

\section{v. Sinusoidal Model 2}

Sinusoidal model 2 şu şekilde yazılabilir.

$$
L_{i j}=a_{0}+a_{1} j+a_{2} \sin \omega j
$$

Yukarıdaki modelin aşağıdaki şartları sağlaması beklenir.

$$
\begin{array}{ll}
\text { a. } & j=0 \text { ise } L_{i j}=L_{i 0} \\
\text { b. } & j=n \text { ise } L_{i j}=L_{i n} \\
\text { c. } & \left(\frac{d L_{i j}}{d j}\right)_{j=\frac{n}{2}}=0
\end{array}
$$

$$
\text { d. } \quad\left(\frac{d^{2} L_{i j}}{d j^{2}}\right)_{j=\frac{n}{2}}=0
$$

Yukarıdaki şartları sağlayan model aşağıdaki şekilde sonuçlanır.

$$
\begin{aligned}
L_{i j}= & L_{i 0}+\frac{L_{i n}-L_{i 0}}{n} j+ \\
& \frac{L_{i n}-L_{i 0}}{2 \pi} \sin \frac{2 \pi}{n} j
\end{aligned}
$$

\section{vi. Sinusoidal Model 3}

Başka bir sinusoidal model de şu şekilde ifade edilebilir:

$$
L_{i j}=a_{0}+a_{1} \sin \omega_{1} j+a_{2} \cos \omega_{2} j
$$

Aşağıdaki şartların sağlanması istenir.

$$
\begin{array}{ll}
\text { a. } & j=0 \text { ise } L_{i j}=L_{i 0} \\
\text { b. } & j=n \text { ise } L_{i j}=L_{i n} \\
\text { c. } & \left(\frac{d L_{i j}}{d j}\right)_{j=0}=0 \\
\text { d. } & \left(\frac{d L_{i j}}{d j}\right)_{j=n}=0
\end{array}
$$

Yukarıdaki şartların uygulanmasıyla şu sonuç elde edilir:

$$
L_{i j}=\frac{L_{i 0}+L_{i n}}{2}-\frac{L_{i n}-L_{i 0}}{2} \cos \frac{\pi}{n} j
$$

\section{vii. Kübik Model}

Kübik model aşağıdaki şekilde ifade edilir:

$$
L_{i j}=a_{0}+a_{1} j+a_{2} j^{2}+a_{3} j^{3}
$$

Bu modelin aşağıdaki şartları sağlaması istenir:

$$
\begin{array}{ll}
\text { a. } & j=0 \text { ise } L_{i j}=L_{i 0} \\
\text { b. } & j=n \text { ise } L_{i j}=L_{i n} \\
\text { c. } & \left(\frac{d L_{i j}}{d j}\right)_{j=\frac{n}{2}}=0 \\
\text { d. } & \left(\frac{d^{2} L_{i j}}{d j^{2}}\right)_{j=\frac{n}{2}}=0
\end{array}
$$


Yukarıdaki koşulların uygulanmasıyla şu bağıntı elde edilir:

$$
\begin{aligned}
L_{i j}= & L_{i 0}+3\left(L_{i n}-L_{i 0}\right)\left(\frac{j}{n}\right)- \\
& 6\left(L_{i n}-L_{i 0}\right)\left(\frac{j}{n}\right)^{2}+ \\
& 4\left(L_{i n}-L_{i 0}\right)\left(\frac{j}{n}\right)^{3}
\end{aligned}
$$

\section{viii. Beşinci Derece Model}

Adımlara bağlı olarak beşinci derece model aşağıdaki şekilde ifade edilir:

$$
\begin{aligned}
L_{i j}= & a_{0}+a_{1} j+a_{2} j^{2}+a_{3} j^{3}+ \\
& a_{4} j^{4}+a_{5} j^{5}
\end{aligned}
$$

Bu modelde aşağıdaki şartların sağlanması istenir:

$$
\begin{array}{ll}
\text { a. } & j=0 \text { ise } L_{i j}=L_{i 0} \\
\text { b. } & j=n \text { ise } L_{i j}=L_{i n} \\
\text { c. } & \left(\frac{d L_{i j}}{d j}\right)_{j=0}=0 \\
\text { d. } & \left(\frac{d L_{i j}}{d j}\right)_{j=n}=0 \\
\text { e. } & \left(\frac{d^{2} L_{i j}}{d j^{2}}\right)_{j=0}=0 \\
\text { f. } & \left(\frac{d^{2} L_{i j}}{d j^{2}}\right)_{j=n}=0
\end{array}
$$

Yukarıdaki şartların uygulanmasıyla (13) nolu fonksiyon aşağıdaki şekli alır:

$$
\begin{array}{r}
L_{i j}=L_{i 0}+10\left(L_{i n}-L_{i 0}\right)\left(\frac{j}{n}\right)^{3}- \\
15\left(L_{i n}-L_{i 0}\right)\left(\frac{j}{n}\right)^{4} \\
+6\left(L_{i n}-L_{i 0}\right)\left(\frac{j}{n}\right)^{5}
\end{array}
$$

\section{SAYISAL ÖRNEKLER}

\section{Örnek 1:}

Bu örneğin verileri bir çizim programı yardımıyla hipotetik olarak elde edilmiştir ve girdi değerleri aşağıdaki gibidir;

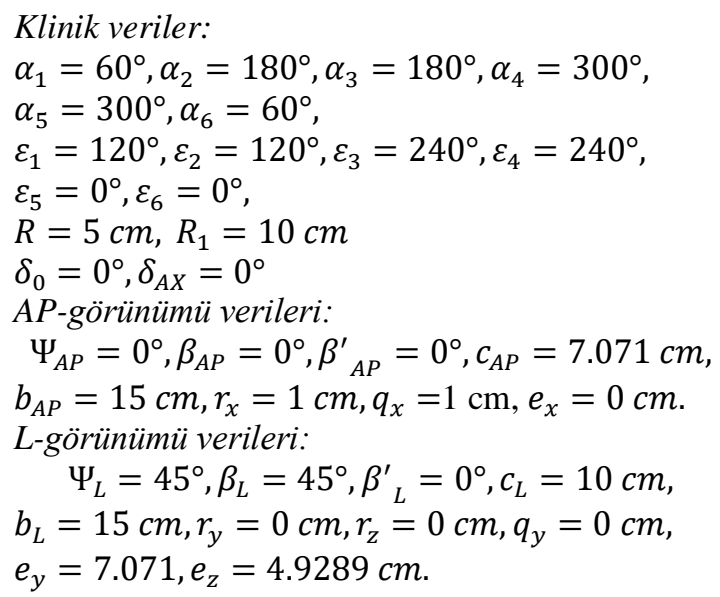

Şekil 4a'da bu verilere ait olan fiksatör kurgusunun 3 boyutlu çizimi görülmektedir. Sağlıksız konumdan sağlıklı konuma gitmek için de dört farklı tedavi yolu gösterilmiştir. Bu yollar ise çubuk boylarının doğrusal model (Şekil 5a, Şekil 4b), artan parabolik model (Şekil 5b, Şekil 4c), sinusoidal model \#2 (Şekil 5c, Şekil 4d) ve karma model (Şekil 5d, Şekil 4e) ile değiştirilmesiyle elde edilmiştir. Karma modelde her bir çubuk boyları birbirinden bağımsız olarak faklı veya kısmen aynı olacak şekilde fonksiyonlarla değiştirilir. $\mathrm{Bu}$ sayede distal fragman ucunun tedavi süresince çok farklı yolları takip etmesi sağlanabilir. Bu örnekteki karma modelde birinci çubuk artan parabolik modele göre, ikinci çubuk sinusoidal model \#1e göre, üçüncü çubuk azalan parabolik modele göre, dördüncü çubuk kübik modele göre, beşinci çubuk doğrusal modele göre ve altıncı çubuk da azalan parabolik modele göre değiştirilmiştir.

\section{Örnek 2:}

$\mathrm{Bu}$ örneğe ait olan veriler gerçek X-ray görüntülerinden elde edilmiştir ve girdi değerleri aşağıdaki gibidir;

$$
\begin{aligned}
& \text { Klinik veriler: } \\
& \alpha_{1}=90^{\circ}, \alpha_{2}=110^{\circ}, \alpha_{3}=210^{\circ}, \alpha_{4}=230^{\circ}, \\
& \alpha_{5}=330^{\circ}, \alpha_{6}=350^{\circ}, \\
& \varepsilon_{1}=0^{\circ}, \varepsilon_{2}=100^{\circ}, \varepsilon_{3}=120^{\circ}, \varepsilon_{4}=220^{\circ}, \\
& \varepsilon_{5}=240^{\circ}, \varepsilon_{6}=340^{\circ}, \\
& R=7.25 \mathrm{~cm}, R_{1}=7.25 \mathrm{~cm} \\
& \delta_{0}=69^{\circ}, \delta_{A X}=27^{\circ}
\end{aligned}
$$


AP-görünümü verileri:

$\Psi_{A P}=-1.21^{\circ}, \beta_{A P}=-4.23^{\circ}, \beta^{\prime}{ }_{A P}=-4.70^{\circ}$,

$r_{x}=0.381 \mathrm{~cm}, q_{x}=-1.071 \mathrm{~cm}, e_{x}=2.619 \mathrm{~cm}$.

L-görünümü verileri:

$\Psi_{L}=5.48^{\circ}, \beta_{L}=0.03^{\circ}, \beta^{\prime}{ }_{L}=4.41^{\circ}$,

$c_{L}=9.643 \mathrm{~cm}, b_{L}=3.55 \mathrm{~cm}, r_{y}=0.32 \mathrm{~cm}$,

$r_{z}=0.003 \mathrm{~cm}, q_{y}=-0.738 \mathrm{~cm}, e_{y}=2.714$,

$e_{z}=2.619 \mathrm{~cm}$

Şekil 4f'de bu verilere ait olan fiksatör kurgusunun 3 boyutlu çizimi görülmektedir. Sağlıksız konumdan sağlıklı konuma gitmek için de üç farklı tedavi yolu gösterilmiştir. Bu yollar ise çubuk boylarının kübik model (Şekil-5e, Şekil-4g), sinusoidal model \#1 (Şekil-5f, Şekil-4h) ve karma model (Şekil-5g, Şekil-4i) ile değiştirilmesiyle elde edilmiştir. Bu örnekteki karma modelde birinci çubuk azalan parabolik modele göre, ikinci çubuk sinusoidal model \#1e göre, üçüncü çubuk sinusoidal model \#2ye göre, dördüncü çubuk sinusoidal model \#3e göre, beşinci çubuk doğrusal modele göre ve altıncı çubuk da kübik modele göre değiştirilmiştir.

\section{SONUÇLAR}

$\mathrm{Bu}$ çalışmada önerilen 8 faklı model, distal fragmanın tedavi süresince izleyebileceği $8^{6}$ adet yörüngeye olanak sağlamaktadır. Böylelikle kemik ucunun günlük kat edeceği yol miktarı tedavinin farklı aşamalarında farklı büyüklükte olacak şekilde ayarlanabilecektir. Bunun yanı sıra ortopediste farklı kullanım opsiyonları sunarak daha esnek bir kullanım imkanı sağlayacaktır. Ayrıca, çubuk uzunluklarının bu modellere göre değiştirilmesi fiksatörün tekil konuma gelme ihtimalini de azaltmaktadır. Mevcut 3-boyutlu simülasyon sayesinde ortopedist, yaptığg fiksatör kurgusunun tedavi süresindeki durumlarını daha tedaviye başlamadan önce gözlemleyebilecek ve muhtemel bir müdahale ihtimalini öngörebilecektir.

\section{TARTIŞMA}

$\mathrm{Bu}$ çalışmada bahsedilen yöntem ile kurgulanan harici fiksatör sistemi, olanak sağladığı farklı tedavi süreçleri sayesinde, günümüzde kullanılmakta olan sistemlerden üstün olan özelliklere sahiptir. Öncelikle, mevcut sistemlerden farklı olarak, öngörülen tedavi sürecinin tüm adımlarında tekillik analizi yapılmaktadır ve fiksatörün süreç boyunca tekil konuma gelmeyeceği garanti altına alınmıştır. Ayrıca distal fragman ucunun tedavinin faklı safhalarında farklı hızlarda hareket etmesine olanak sağlayan 8 adet matematiksel model sayesinde klinik uygulamaların çeşitlendirilebileceği gösterilmiştir. Bununla birlikte, mevcut sistemlerde sadece iki boyutta görselleştirilmiş olan tedavi sürecinin 3 boyutlu simülasyonu gerçekleştirilmiştir.

\section{TEŞEKKÜR}

$\mathrm{Bu}$ çalışma TÜBİTAK tarafindan desteklenen 112M406 numaralı proje kapsamında gerçekleştirilmiştir.

\section{KAYNAKLAR}

1. Stewart, D., 1965. A platform with 6 degrees of freedom, Proc. of The Institution of Mechanical Engineers, Vol.180, No. 15, pp. 371-386.

2. Burny, F., Bourgouis, R., Donkerwolcke, M., 1982. Elastic Fixation: A Biomechanical Study of the Half-Frame, In Seligson, D., Pope, M.H., (Eds) Concepts in External Fixation, Grune and Stratton, New York, pp:67-77.

3. Behrens, F. 1981. External Skeletal Fixation; In American Academy of Orthopaedic Surgeons Instructional Course Lectures, Vol.30, The CU Mosley Co., St. Louis.

4. Donald, G., Seligson, D., 1982. Fixateur Systems in Current Use in Concepts in External Fixation, (Eds: Seligson, D., Pope, M.) Grune and Stratton, pp:293-308.

5. Pope, M.H., Evans, M., 1982. Design Considerations in External Fixation, in Concept in External Fixation (Eds: Seligson, D., Pope, M.), Grune and Stratton, New York, pp:109 138.

6. Hughes, J.L., Sauer, B.W., 1982. Wagner Apparatus: A Portable Traction Device in 


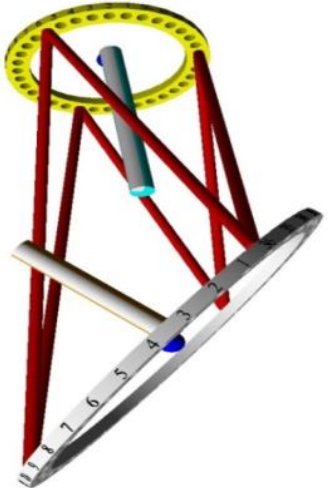

(a)

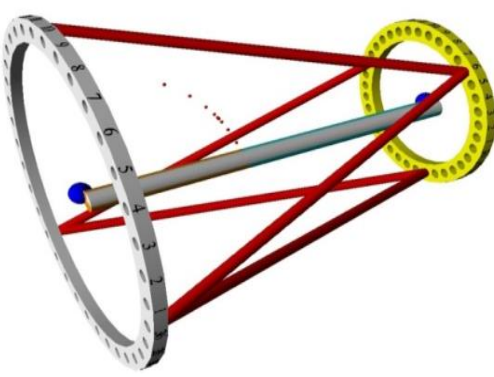

(d)

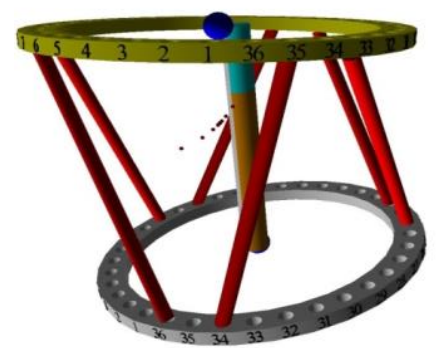

(g)

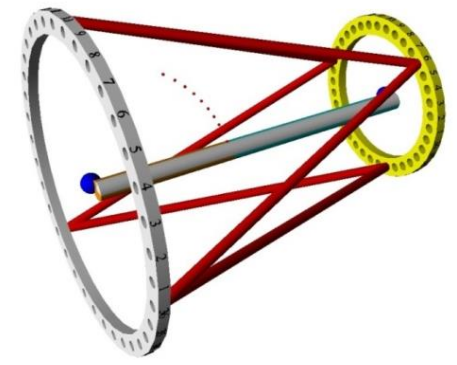

(b)

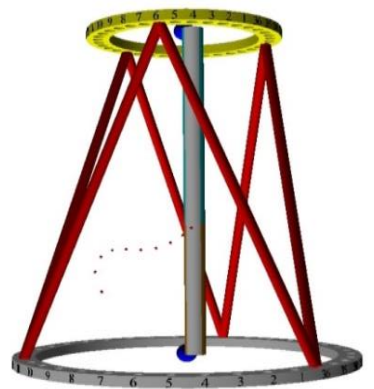

(e)

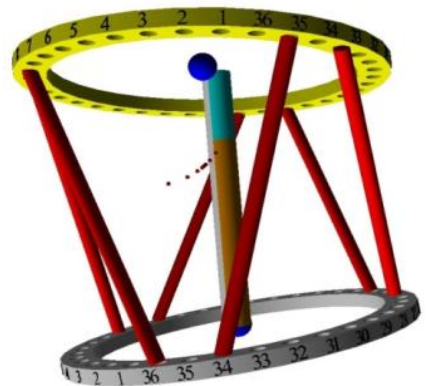

(h)

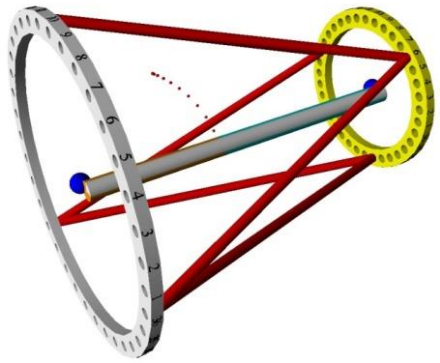

(c)

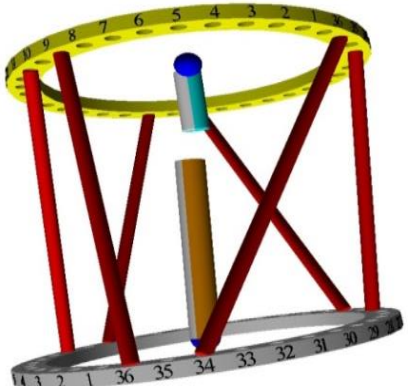

(f)

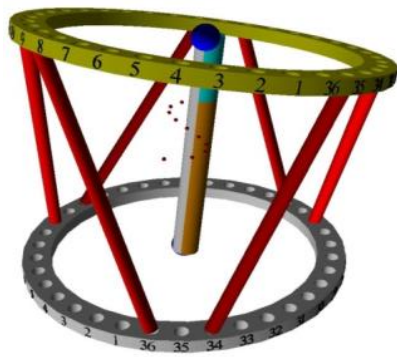

(1)

Şekil 4. (a) Örnek-1 için başlangıç konumu, (b) Örnek-1 Doğrusal model için çubukların hizalanması ve distal fragmanın izlediği yol, (c) Örnek-1 Artan parabolik model için çubukların hizalanması ve distal fragmanın izlediği yol, (d) Örnek-1 sinusoidal model \#2 için çubukların hizalanması ve distal fragmanın izlediği yol, (e) Örnek-1 karma model için çubukların hizalanması ve distal fragmanın izlediği yol (f) Örnek-2 için başlangıç konumu, (g) Örnek-2 kübik model için çubukların hizalanması ve distal fragmanın izlediği yol, (h) Örnek-2 sinusoidal model \#1 için çubukların hizalanması ve distal fragmanın izlediği yol, (i) Örnek-2 karma model için çubukların hizalanması ve distal fragmanın izlediği yol 


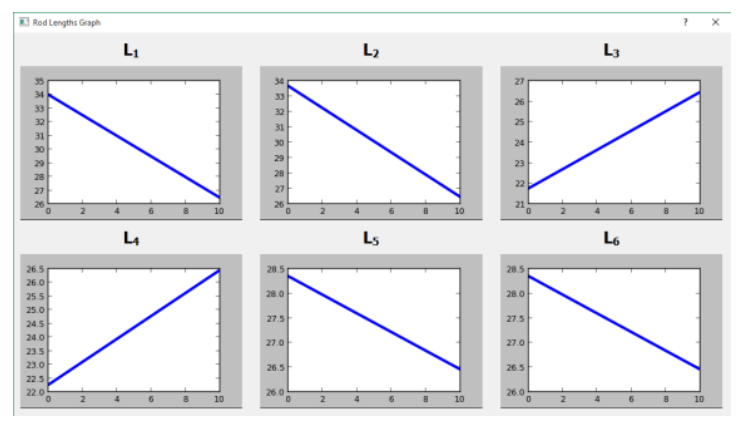

(a)

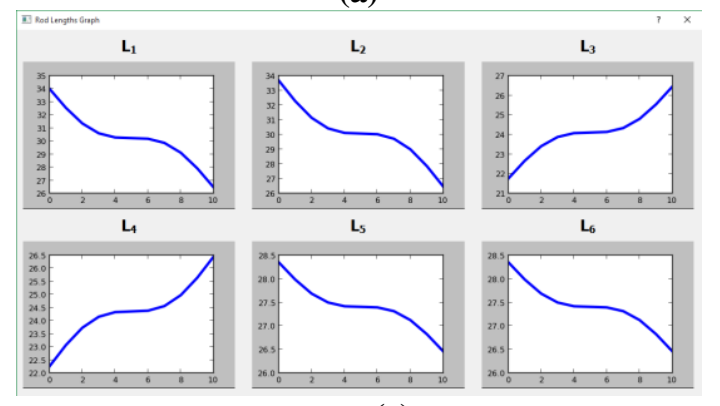

(c)

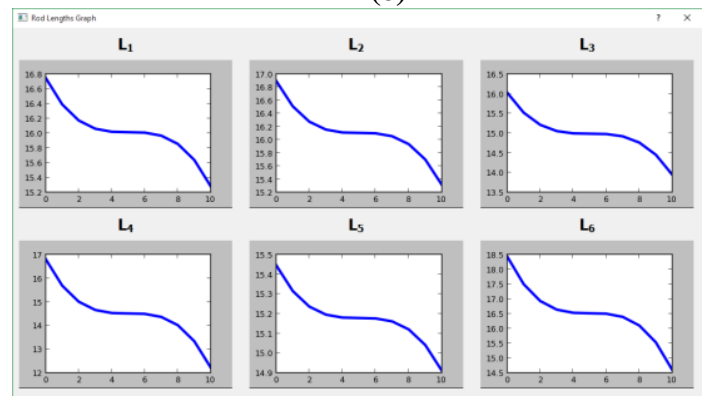

(e)

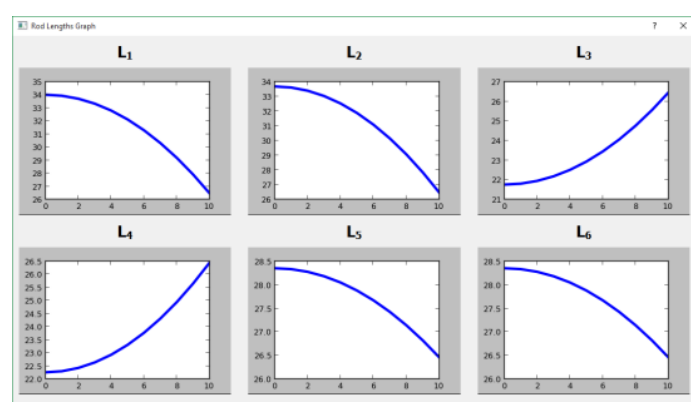

(b)

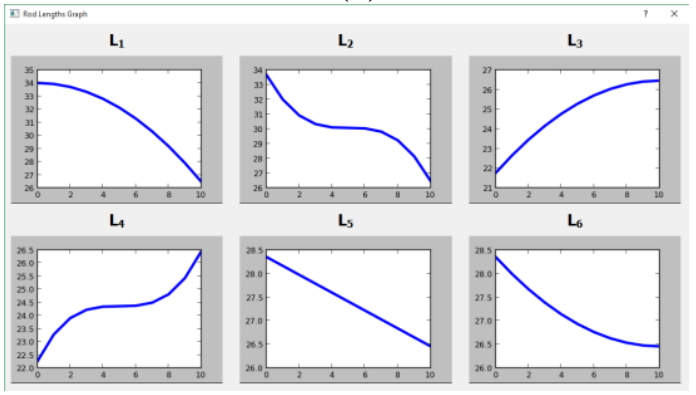

(d)

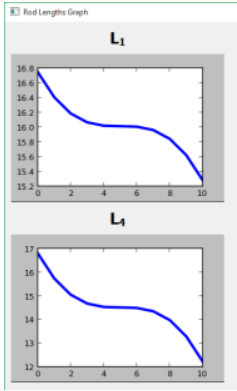

$\mathrm{L}_{2}$

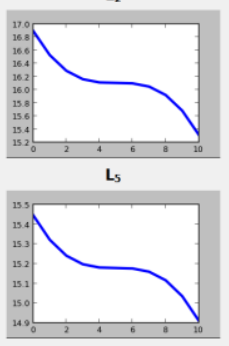

(f)

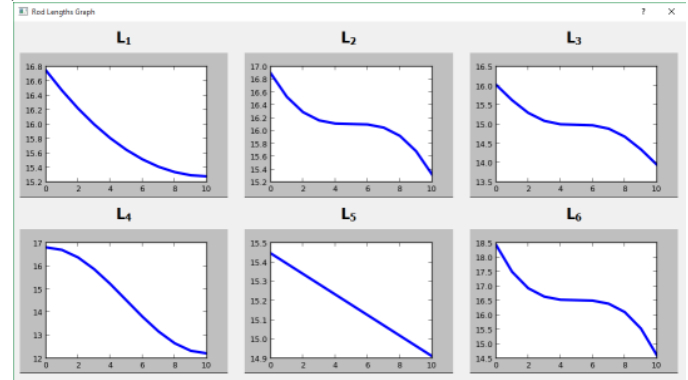

(g)

Şekil 5. (a) Örnek-1 Doğrusal model için çubuk boylarının değişim grafiği, (b) Örnek-1 Artan parabolik model için çubuk boylarının değişim grafiği, (c) Örnek-1 sinusoidal model \#2 için çubuk boylarının değişimgrafiği, (d) Örnek-1 karma model için çubuk boylarının değişim grafiği, (e) Örnek-2 kübik model için çubukboylarının değişim grafiği, (f) Örnek-2 sinusoidal model \#1 için çubuk boylarının değişim grafiği, (g) Örnek-2 karma model için çubuk boylarının değişim grafiği 
Concepts in External Fixation (Eds: Seligson, D., Pope, M.H.) Grune and Stratton, New York, pp:203-218,

7. Letournel, E., 1982. The Judeth Fixateur for Fractures of the Ankle, in Concepts in External Fixation, Grune and Stratton, New York, pp:247-266,

8. Behrens, F., 1982. Unilateral External Fixation For Severe Lower Extremity Lesions: Experience with the ASIF (AO) Tubular Frame, in Concepts in External Fixation (Eds: Seligson, D. and Pope, M.) Grune and Stratton, New York, pp:279-292.

9. Fernandez, A.A., 1985. External Fixation of the Leg Using Unilateral Biplanar Frames, Arch. Orthop. Trauma Surg., 104 Springer Verlag, pp:182-186.

10. Ilizarov, G., 1992. Transosseons. Berlin, Springer Verlag.

11. Çakmak, M., Kocaoğlu, M., 1999. İlizarov Cerrahisi ve Prensipleri, İstanbul.

12. Aydın, A., İbrikçi, T., Akçalı, İ.D., 2011. A Hybrid Image Processing System for X-ray Images of An External Fixator, Computer Methods in Biomechanics and Biomedical Engineering, 15:7, pp. 753-759,

13. Akçalı, İ.D., Şahlar M.O., Ün, M.K., Aydın, A., İbrikçi, T., Esen, R., Gülşen, M., Bayram, H., 2009. A Mathematical Model in the Implementation of a Stewart Platform as an External Fixator, Medical Physics and Biomedical Engineering World Congress, IFMBE Proceedings,Springer, Vol. 25, pp: 708-711, 7-12 September, Munich Germany.

14. Mutlu, H., Akçalı, İ.D., Gülşen, M., 2006. A Mathematical Model for the Use of a GoughStewart Platform Mechanism as a Fixator. J. of Engineering Mathematics, pp:119-143.

15. Dasgupta, B., Mruthyunjaya, T. S., 1998. Singularity-Free Path Planning for the Stewart Platform Manipulator, Mech. Mach. Theory Vol. 33, No. 6, pp. 711-725.

16. Sarıül, A. S., Güneri, B., 2014. Some geometric, kinematic, and dynamic considerations on Stewart-Gough platforms with singularity analysis., Robotica, 32, pp 953-966.
17.Li, Y., Wang, Y., 2014. Eliminating Singularity of a Parallel Driving Mechanism of Axisymmetric Vectoring Exhaust Nozzle., Proc. of the Inst. of Mech. Eng., Part G: J. of Aerospace Engineering, vol. 228, no. 12, pp: 2300-2309, Oct.

18. Coste, M., Moussa, S., 2015. On the Rationality of the Singularity Locus of a Gough-Stewart Platform-Biplanar Case., Mechanism and Machine Theory, vol: 87, pp.82-92.

19. St-Onge, B. M., Gosselin, C. M., 2000. Singularity Analysis and Representation of the General Gough- Stewart Platform, The International Journal of Robotics Research, Vol. 19, No. 3, pp. 271-288.

20. Dash, A.K., Chen, I.M., Yeo, S.H., Yang, G., 2005. Workspace Generation and Planning Singularity-Free Path for Parallel Manipulators., Mechanism and Machine Theory Vol: 40, pp: 776-805.

21. Akçalı, İ.D., Avşar, E., Ün, M.K., Aydın, A., İbrikçi, T., Mutlu, H., Biçer, Ö.S., Özkan, C., Durmaz, A., 2014. Displacement Analysis of Robotic Frames for Reliable and Versatile use as External Fixator, The 4th Annual IEEE International Conference on Cyber Technology in Automation, Control and Intelligent Systems, Hong Kong, China, June 4-7.

22. Akçalı, İ.D., Avşar, E., Durmaz, A., Aydin, A., Ün, M.K., İbrikçi, T., Mutlu, H., Özkan, C., Biçer, Ö.S., 2015. Singularity Detection in an External Fixator of Gough-Stewart Platform Type, International Conference on Innovative Technologies, IN-TECH 2015, pp.284-287, Dubrovnik, Hırvatistan, 9-11 Eylül.

23. Akçalı, İ.D., Avşar, E., Durmaz, A., Sağdıç, İ., Aydin, A., Ün, M.K., İbrikçi, T., Özkan, C., Biçer, Ö.S., 2015. Fiksatörün En Yakın Noktalar Yaklaşımıyla Tekillik Denetimi, Tıp Teknolojileri Ulusal Kongresi, TIPTEKNO'15, ss.404-407, Muğla, Türkiye, 15-18 Ekim.

24. Barkana, D. E., 2010. Design and Implementation of a Control Architecture for Robot-Assisted Orthopaedic Surgery., Int. J. Med. Robotics Comput. Assist. Surg., Vol: 6, pp: 42-56. 
